\title{
Group B Streptococcus Colonisation, Prevalence, Associated Risk Factors and Antimicrobial Susceptibility Pattern Among Pregnant Women Attending Antenatal Care at Dschang District Hospital, West Region of Cameroun: A hospital-based Cross Sectional Study
}

Leonard Sama $^{1}$, michel Noubom ${ }^{1}$, Christelle KENNE ${ }^{1}$, Thibau Tchouangueu ${ }^{1}$, omer Ngouateu $^{1}$, Albert Atsamoh ${ }^{1}$, osein karimo ${ }^{1}$, and christopher tume ${ }^{1}$

${ }^{1}$ Affiliation not available

February 18, 2021

\begin{abstract}
Background: Group B streptococcus (GBS), also name as Streptococcus agalactiae, is a gram-positive bacterium know for it capacity to colonises the vaginal and rectal areas of the mother and is a leading cause of neonatal mortality and morbidity. This study aimed at determining the prevalence, associated risk factors and antimicrobial susceptibility of GBS colonization among pregnant women attending antenatal care at Dschang District Hospital. Methods: This hospital-base cross-sectional study targeted pregnant women population attending hospitals for routine prenatal testing using a multistage sampling method. Pregnant women at $23.46 \pm 6.44$ weeks gestation completed a questionnaire and vaginal swabs were obtained for GBS analysis. Data were analysed using chi-squared $\left(\chi^{2}\right)$ test or the Fisher's exact test when appropriate and the multivariable logistic regression models. Results: The colonisation rate of GBS among pregnant women was 8.69\%. Induce abortion (odds ratio $[\mathrm{CI}]=3.09,95 \%[1.56-6.21])$, Spontaneaous abortions $(\mathrm{OR}=2.82,95 \%$ CI 1.14-7.29), Stillborn (OR [CI $]=7.75,95 \%[2.61-$ $21.71])$, Fever $(\mathrm{OR}[\mathrm{CI}]=0.37,95 \%[0.19-0.71])$ and anemia $(\mathrm{OR}[\mathrm{CI}]=0.22,95 \%[0.12-0.43])$ were found to be influencing factors associated with GBS colonisation. Conclusion: Our findings suggest that none of the studied factors were significantly associated with GBS colonisation. Further longitudinal research is needed to establish the causal relationship and its biological mechanisms. Keys words: Group B Streptococcus, Prevalence, Risk Factors, Antimicrobial Susceptibility, Pregnant Women
\end{abstract}

Group B Streptococcus Colonisation, Prevalence, Associated Risk Factors and Antimicrobial Susceptibility Pattern Among Pregnant Women Attending Antenatal Care at Dschang District Hospital, West Region of Cameroun: A hospital-based Cross Sectional Study

Leonard Fonkeng Sama ${ }^{*}$, Michel Noubom ${ }^{2}$, Christelle Kenne ${ }^{2}$, Thibau Flaurant Tchouangueu $^{1}$, Omer Bebe Ngouateu $^{3}$, Albert Donatien Atsamo ${ }^{3}$ Ousenu Karimo ${ }^{1}$ and Christopher Bonglavnyuy Tume $\mathrm{e}^{1,4}$

${ }^{1}$ Unit of Microbiology and Antimicrobial Substances, Department of Biochemistry, University of Dschang

${ }^{2}$ Faculty of Medical and pharmaceutical Sciences, Department of Microbiology and Immunology, University of Dschang, Cameroon

${ }^{3}$ Faculty of Science, Department of Animal Biology and Physiology, University of Yaoundé I,

${ }^{4}$ University of Bamenda, Faculty of Science, Department of Biochemistry, University of Bamenda, Cameroon

*Corresponding author: Leonard Fonkeng Sama: safole2000@yahoo.fr 
Other authors e-mails:

Michel Noubom: michelnoubom@yahoo.fr

Kenne Christelle: michel.noubom@yahoo.fr

Thibau Flaurant Tchouangueu: ttchouangueu@gmail.com

Omer Bebe Ngouateu: ob_ngouateu@yahoo.fr

Albert Donatien Atsamo: atsamoalbert@yahoo.fr

Ousenu Karimo: ousenukarimo90@gmail.com

Christopher B. Tume: tumechrist@yahoo.com

\section{ABSTRACT}

Background: Group B streptococcus (GBS), also name as Streptococcus agalactiae, is a gram-positive bacterium know for it capacity to colonises the vaginal and rectal areas of the mother and is a leading cause of neonatal mortality and morbidity. This study aimed at determining the prevalence, associated risk factors and antimicrobial susceptibility of GBS colonization among pregnant women attending antenatal care at Dschang District Hospital.

Methods: This hospital-base cross-sectional study targeted pregnant women population attending hospitals for routine prenatal testing using a multistage sampling method. Pregnant women at $23.46 \pm 6.44$ weeks gestation completed a questionnaire and vaginal swabs were obtained for GBS analysis. Data were analysed using chi-squared $\left(\chi^{2}\right)$ test or the Fisher's exact test when appropriate and the multivariable logistic regression models.

Results: The colonisation rate of GBS among pregnant women was $8.69 \%$. Induce abortion (odds ratio [CI] $=3.09,95 \%$ [1.56-6.21]), Spontaneaous abortions (OR=2.82, 95\% CI 1.14-7.29), Stillborn (OR [CI $]=7.75$, $95 \%[2.61-21.71])$, Fever $(\mathrm{OR}[\mathrm{CI}]=0.37,95 \%[0.19-0.71])$ and anemia $(\mathrm{OR}[\mathrm{CI}]=0.22,95 \%[0.12-0.43])$ were found to be influencing factors associated with GBS colonisation.

Conclusion : Our findings suggest that none of the studied factors were significantly associated with GBS colonisation. Further longitudinal research is needed to establish the causal relationship and its biological mechanisms.

Keys words: Group B Streptococcus, Prevalence, Risk Factors, Antimicrobial Susceptibility, Pregnant Women

What's known * Few epidemiologic studies have incorporated multi-di-mensional risk factors for GBS colonisation in pregn

\section{INTRODUCTION}

Group B streptococcus (GBS), also name as Streptococcus agalactiae, is a gram-positive bacterium know for its capacity to cause infection of the mother infection, fetus, neonatal sepsis and meningitis ${ }^{1,2}$. Early-onset diseases in infants such like pathogen causes chorioamnionitis ${ }^{3}$, preterm birth $^{4}$, stillbirth ${ }^{5}$, meningitis ${ }^{6}$ are the results of GBS vertical transmission from a colonised mother during or just before delivery. These suggest that, maternal colonisation of the genitourinary tracts by GBS is the primary risk factor for earlyonset diseases causing both early-onset ( $<7$ days of life) and late-onset (7-89 days of life) neonatal sepsis ${ }^{7}$ but also an important cause of premature rupture of membranes, advanced abortion, premature birth and a series of adverse of pregnancy outcomes in women ${ }^{8,9}$. According to studies, GBS colonization in pregnant women varies from place to place and ranged from $2.0 \%$ to $32.0 \%^{1}$, hence the prevalence of a neighbouring country or continent cannot be used to estimate the prevalence in our setting. Contradicting prevalence have been revealed according to specific sites in sub-Saharan Africa ${ }^{10}$ though according to Chaudhry et al. this prevalence was found to be $19 \%^{11}$. In Cameroon, few studies have been conducted on GBS with variable 
prevalence from $7.7 \%$ to $14 \%$ in Yaoundé ${ }^{12,13}$ but in the West Region of Cameroon, no information exist on GBS. Awareness of GBS prevalence in specific parts of Cameroon remain an important asset to clinicians, in decision-making about the need for genital or anogenital GBS screening of pregnant women attending antenatal clinic while identifying associated factors. This will should however lead to targeted screening of high risk pregnant women using minimum resources available, all of which will hopefully contribute the reduction of cases of neonatal sepsis caused by GBS infection at Dschang Distric Hospital. Currently in Cameroon, there is no policy for routine GBS screening of pregnant women attending antenatal care but also no standardized screening method despite the high perinatal mortality and no treatment is offered to those affected. If a policy is formulated and effected, this would contribute to the prevention of live births who get serious GBS neonatal infection with increased mortality and morbidity.

This study aimed at determining the prevalence, associated risk factors and antimicrobial susceptibility of GBS colonization among pregnant women attending antenatal care at Dschang District Hospital (DDH) which may provide implications for the development of improved and rational interventions for GBS infection and disease.

\section{METHODS}

\subsection{STUDY DESIGN AND POPULATION}

This hospital-base cross-sectional study was conducted from January to July 2019 and targeted pregnant women population attending antenatal routine care at the DDH, known to be the main hospital of the Menoua division in the West Region of Cameroon, with an estimated 100 monthly. All women that accepted to participate to this study voluntarily signed an informed consent form irrelative to the gestation age.

\subsection{DATA AND SPECIMEN COLLECTION}

Local research trained staff interviewed recruited pregnant women using a standardized questionnaire to record demographic characteristics, obstetric factors, medication history or disease history. Specimens where collected from the lower vagina of pregnant women using sterilised disposable cotton swabs. Each swab was then immerged into 2-3 ml of the Brain Heart Infusion Broth (BHIB), placed into the specimen transportation flask and transported to the lab within $30 \mathrm{~min}$.

\subsection{BACTERIAL STRAINS}

Collected samples were inoculated into blood agar plates supplemented with colistin nalidixic acid and incubated for $18-24 \mathrm{~h}$ at $37^{\circ} \mathrm{C}$ in a candle jar enriched with $5 \%$ Carbon-dioxide. All greyish, smooth, small and non-pigmented colonies with a visible zone of beta hemolysis appearing $24 \mathrm{~h}$ after incubation were isolated, further incubation and their reactivity to catalase evaluated. Colonies with a negative catalase reactivity after further incubation were then isolated and used for the confirmatory diagnosis using the Pastorex strep kit (BIO-RAD). Colonies which agglutinated with the GBS latex reagent were considered positive.

The resulting isolates were then used for antibiotic susceptibility testing by the Kirby Bauer disc difusion method. The antibiotics was tested and their respective diameters of inhibitions were measure and compare to those of the French microbiology society as of 2018 (SFM ; EUCAST)

\subsection{ANTIMICROBIAL SUSCEPTIBILITY TESTING}

Antimicrobial susceptibility testing was performed according to Clinical and Laboratory Standard Institute Guidelines (CLSI, 2014) by disk diffusion ${ }^{14}$. A suspension of the test organism was prepared by removing 3-5 colonies from a pure culture plate by emulsifying in $3 \mathrm{ml}$ of sterile physiological saline and was diluted with saline until the turbidity of the suspension become matched with turbidity standard equivalent to 0.5 McFarland and inoculated on Muller-Hinton agar (MHA, Oxoid, England) with 5\% sheep's blood. After the excess suspension was removed by gentle rotation of the swab against the surface of the tube, the swab was then used to distribute the bacteria evenly over the entire surface of MHA supplemented with $5 \%$ sheep blood. The inoculated plates were left at room temperature to dry for 3-5 minutes and a set of 6 antibiotic 
discs in each plate were placed with the concentration of penicillin $\mathrm{G}(10 \mu \mathrm{g})$, gentamicin $(\mathrm{CN})(10 \mu \mathrm{g})$, erythromycin (E) $(15 \mu \mathrm{g})$, clindamycin (DA) $(2 \mu \mathrm{g})$, tetracyclin $(10 \mu \mathrm{g})$, norfloxacin $(10 \mu \mathrm{g})$, Chloramphenicol (C) $(30 \mu \mathrm{g})$, pristicin $(10 \mu \mathrm{g})$, steptomycin $(10 \mu \mathrm{g})$, rifampicin $(10 \mu \mathrm{g})$ and incubated at $35-37{ }^{\circ} \mathrm{C}$ with $5 \%$ $\mathrm{CO}_{2}$ atmosphere by candle jar for 18-24 hours. The zone of growth inhibition was measured using rulers. The sizes of the inhibition zones were graded according to the CLSI 2014 and interpreted as susceptible, intermediate or resistant ${ }^{14}$ (All of the antibiotics used in the investigation are product of Oxoid, England and HIMEDIA).

\subsection{STUDY VARIABLES}

The main outcome variable was GBS colonization, defined as positive sample culture from the lower vagina duct. Potential interfering factors were chosen a priori on the basis of literature review, including age (years), marrietal status (single, married, widow), level of education (Primary, secondary and high education), income ( low, moderate and hight) occupation ( Student, housewife,femer, business, nurse, teacher,hustle, other), gestationnal age (in weeks), parity (number of previous births), induce abortion (yes or no), spontaneaous abortions (yes, no), stillborn (yes, no), previous surgy (yes, no), electropic pregnancy (yes, no), induce labour (yes, no), PROM (yes, no), Number of prenatal visit, used of contraceptive (yes, no), Used of antibiotic (yes, no), fever (yes, no), diabetic (yes, no), HIV status (yes, no), heart disease (yes, no), anemia (yes, no) and UTI during pregnancy (yes, no)

\subsection{DATA ANALYSIS}

Categorical variables of pregnant women included in this study were compared using Pearson's chi-squared $\left(\chi^{2}\right)$ test or Fisher's exact test when appropriate. Multivariable logistic regression models were fitted to assess correlations between potential factors and GBS colonisation and were expressed by odds ratios (ORs) and $95 \%$ confidence intervals (CIs). The level of statistical significance was set at $\mathrm{p}<0.05$. Satatistical analysis was performed using Graphpad prism version 8.0.2 sofware.

\subsection{ETHICAL CONSIDERATIONS}

Ethical clearance was obtained from the National Ethical Committee for Research in charge of Human Health (CNERSH), No2019/11/56/CE/CNERSH/SP, Yaoundé Cameroon. Research authorizations were also obtained from all heads of districts in the Menoua division. Research authorization was also granted by the University of Dschang.

\section{RESULTS}

\subsection{CHARACTERISTICS OF THE STUDY PARTICIPANTS}

A total of 621 pregnant women accepted to participate in this study and they all had corresponding both obstetric data and bacteriological cultures. The mean age $( \pm \mathrm{SD})$ of the study population was $26.49 \pm 5.77$ years, and the ages ranged from 16 to 44 years. The mean gestational age ( \pm SD) was $23.46 \pm 6.44$ weeks, and the gestational ages ranged from 8 to 36 weeks. The overall prevalence of GBS colonisation among pregnant women was $8.69 \%(54 / 621)$.

\subsection{DEMOGRAPHIC CHARACTERISTICS OF STUDY PARTICIPANTS AND PREVA- LENCE OF GBS COLONISATION}

Income was positively associated with GBS colonisation ( 55.56 for low vs 44.44 for moderate and $0 \%$ for high, $\mathrm{p}=0.006$ ) whereas Age category, Marrietal status, Level of education and occupation were not associated with GBS colonisation (Table 1).

\subsection{OBSTETRIC FACTORS OR PREGNANCY HISTORY AND GBS COLONISATION}

Concerning obstetric factors, GBS colonisation was found to be associated with Parity $(44.44 \%$ for none vs $55.56 \%$ for $1-3$ and $0.00 \%$ for above $4, \mathrm{p}=0.006)$, induce abortion $(22.22 \%$ vs $77.78 \%, \mathrm{p}=0.003)$, Spontaneaous abortions $(11.11 \%$ vs $88.89 \%, p=0.0037)$, Stillborn $(11.11 \%$ vs $88.89 \%, p=0.000)$ and number of prenatal visit $(\mathrm{p}=0.0178)$ whereas GBS colonisation was not associated with premature $(\mathrm{p}>0.999)$, surgy 
( $\mathrm{p}>0.999)$, ectopic pregnancy ( $\mathrm{p}>0.999)$, Induced labour $(\mathrm{p}>0.999)$, PROM ( $\mathrm{p}>0.999)$ and use of contraceptive $(\mathrm{p}=0.202)$ (Table 2$)$.

\subsection{MEDICATION HISTORY OR DISEASE HISTORY AND GBS COLONISATION}

Compared with Fever, women with no fever during pregnancy experienced a higher rate of GBS colonisation ( $56.61 \%$ vs $43.39 \%, \mathrm{p}=0.002)$. Similarly, women with no anemia during pregnancy experienced a higher rate of GBS colonisation $(72.22 \%$ vs $27.78 \%, \mathrm{p}<0.000)$. But no significant relation was observed for Diabetic, HIV status, Heart disease and UTI during pregnancy (Table 3).

\subsection{RISK FACTORS ASSOCIATED TO GBS COLONISATION USING A MULTIVARIA- BLE LOGISTIC REGRESSION MODEL}

The multivariable logistic regression model (Table 4) shows that none of the factor study is positively associated to with GBS colonisation.

\subsection{ANTIMICROBIAL SUSCEPTIBILITY TESTING}

Most of the GBS isolates were susceptible to Penecilin G (89\%) and Norfloxacin (83\%). They were all resistant to Gentamicin and Clindamycin whereas erythomycin, tetracyclin and chloramphenicol were found to be resistant at $49 \%, 34 \%$ and $35 \%$ respectively. Streptomycin presented the higher intermediate activity (64\%) folow by Pristinamici (44\%) and Rifampicin (38\%) (Figure 1).

\section{DISCUSSION}

Group B streptococcus colonisation among pregnant women commonness worldwide is highly variable (2.0\%$32.0 \%)^{1}$, depending on regions. In this study, the prevalence of GBS colonisation was $8.69 \%$, which is higher than those reported in previous studies in other regions of Cameroon; including $4 \%$ in a tertiary hospital in Cameroon ${ }^{13}, 7.7 \%$ at the Yaoundé Gyneco-obstetric and Paediatric hospital ${ }^{15}$ and $6,7 \%$ at the Yaoundé General Hospital ${ }^{16}$. Variations between regions could possibly be due to differences in sampling method used, sample size, population variation and geographical difference. However this result is simillar to the $8.5 \%$ repported in Ethiopia ${ }^{17}$ but higher than the $4.9 \%$ reported in a hospital-based study and implications for primary care Shenzhen, China ${ }^{18}$ and lower than 19.5\% reported in Amman, Jordan ${ }^{19}, 13.7 \%$ repported by Mekelle, $20.86 \%$ by Hawassa and $19 \%$ by Jimma with overall all in Ethiopia $20,21,22$ and the $28.8 \%$ determined in Uganda ${ }^{23}$. These variations between countries could be due to differences in culture methods, populations investigated, sample size and sampling sites. For example, the prevalence of GBS sampled from anogenital was hight in Uganda $(28.8 \%)^{23}$ and sampled from both abdominal skin and ear canal was high in Italy $(62.7 \%)$ and in Gambian (33.7\%) ${ }^{24,25}$ but the prevalence of GBS sampled only from skin/mucosal surface was low in Pakistan (8.5\%) and in Greece (6.6\%), ${ }^{26,27}$ indicating potential differences in GBS colonisation according to the sites of sample collection. It should be noted GBS screening is not a standard care for maternal GBS colonisation during pregnancy and increases the risk of neonatal infection by vertical transmission ${ }^{28}$. The susceptibility to antibiotics has shown that antibiotic prophylaxis could effectively interrupt vertical transmission of GBS and reduce the incidence of GBS infections. Therefore, these findings recommend the need for screening of pregnant women for GBS, so that intrapartum antimicrobial prophylaxis be offered to all GBS-colonised women.

Studies conducted in Cameroon on GBS colonisation in pregnant women have focused on assessing the prevalence $^{12,13,15,16,19}$ but risk factors for GBS colonisation have not been systematically studied. For example, increasing epidemiological studies have demonstrated the relationship between obesity and GBS colonisation in pregnant women ${ }^{1,23}$. The impact of sociodemographics factors on GBS colonisation in pregnant women show the association with the level of income $(\mathrm{p}=0006)$ with high prevalence $(55.56 \%)$ found in patients with low income. This could be due to personal hygiene and environmental sanitation difference between low and high-income settings. The difference may also be related with awareness and behavioral variation. However, in two studies conducted in Zimbabwe showed significant association of GBS colonization among rural residents compared to urban residents ${ }^{29}$. 
The impact of obstetric factors on GBS colonisation in pregnant women is still uncertain since previous results are inconsistent ${ }^{1}$. Several studies revealed no significant differences in colonisation rates according to ectopic pregnancy, induce labour, PROM and used of contraceptive ${ }^{30,31,32,33,34}$ as shown in our results. In some research showed increasing age was significantly associated with lowering rates of GBS colonisation ${ }^{35,36}$. The study from a hospital-based study and implications for primary care revealed that pregnant women had a significantly higher colonisation rate ${ }^{1}$. This corroborate the current findings, eventhough the association was not significant with higher rates of colonisation in the multivariable model. Therefore, these inconsistent results may be influenced by many different cut-off points of gestational age and various structures of the model fitted. However, parity, induced abortion, spontaneaous abortions, stillborn, number of prenatal visits were significantly associated with rates of colonisation in our research. This result is comparable to the result determined in pregnant women in northern India ${ }^{37}$ and also with the study conducted by Dechen TC et al ${ }^{38}$.

Disease history is potential risk factors for GBS colonisation in pregnant women ${ }^{39,40}$. A study in Korea on pregnant women revealed that urinary tract infection and vaginitis were significantly associated with GBS colonisation $^{30}$. Another study in Bukavu also found that both urinary tract infections and HIV seropositivity were associated with higher odds ratios for vaginal colonisation in pregnant women ${ }^{39}$. However, our study found that, HIV seropositivity and UTI during pregnancy were protective factors for GBS colonisation (OR $=0$ and 0.51 successively for HIV and UTI patients). Similar were also shown from a hospital-based study and implications for primary ${ }^{(1)}$. Induced abortion (odds ratio $[\mathrm{OR}]=3.09,95 \%$ CI 1.56-6.21), spontaneaous abortions $(\mathrm{OR}=2.82,95 \%$ CI 1.14-7.29), stillborn $(\mathrm{OR}=7.75,95 \%$ CI $2.61-21.71)$, fever $(\mathrm{OR}=0.37,95 \%$ CI 0.19-0.71) and anemia (OR $=0.22,95 \%$ CI 0.12-0.43).

The potential reasons for these results remain unclear. The underlying biological mechanism and aetiology for these risk factors associated with GBS colonisation is still uncertain. Genitourinary GBS colonisation may occur with respect to hygiene, sexual practice or underlying immune system polymorphisms that reduce innate ability to eliminate the organism ${ }^{41}$, 42 . Future study examines women who are originally negative and then become positive is needed, which may improve our understanding of the risk factors for colonisation.

Results of antibiotic susceptibility testing revealed that almost all strains (89\%) were sensitive to all penicillins G tested. However highest levels of resistance were recorded with gentamicin (100\%) and clindamycin (100\%). Whereas the higher intermediate activity where found with streptomicin (64\%), Pristinamici (44\%) and Rifampicin (38\%). These results showed that beta-lactamines known to be used as ich constitute the recommended first and second line prophylaxis regimen ${ }^{43}$ were all active on the isolated strains. However, Erythromycin which is recommended in case of allergy to beta-Lactamines was not active on some strains. Similar results were reported by Shiferawu et al . in South Ethiopia with $100 \%$ susceptibility of strains to Penicillin $\mathrm{G}^{44}$.

To our knowledge, it is the largest sample studies on this topic in Cameroon to date, and this study provides new insights into the interfering factors associated with GBS colonisation among pregnant women. However, potential limitations also need to be considered. First, only the vagina was used as a sampling site, with a consequence of underestimation of the true prevalence of GBS. However, the latest system review on pregnant women revealed that there was no significant difference in GBS colonisation according to sample sites $(11 \%$ for both vaginal and rectal samples, $11 \%$ for vaginal samples, and $8 \%$ for other samples, $\mathrm{P}=$ $0.070)^{44}$. Second, the study design is a cross-sectional, in which both cause and effect are measured at the same time; therefore, we can only describe associations between influencing factors and GBS colonisation, not a causal conclusion. The pathophysiological mechanisms responsible for the observed associations are unknown, therefore results from this study need to be confirmed in future longitudinal studies. Finally, although it is one of the large sample studies in Cameroon, it only represents data from one hospital in one city. Results from this study need to be verified in future prospective, national, multihospital and multicenter research.

\section{CONCLUSION}

The prevalence of GBS colonisation in pregnant women in this study is not significantly different to that found 
elsewhere in Cameroon, indicating the need for screening of pregnant women for GBS so that intrapartum antimicrobial prophylaxis can be offered to all GBS- colonised women. We found that income, gestationnal age, parity, induce abortion, spontaneaous abortions, spontaneaous abortions, stillborn, number of prenatal visits, fever and anemia were associated with higher rates of GBS colonisation, while UTI and HIV were associated with lower rates of colonisation. However, similar sensitivity to beta lactamines was shown for strains isolated, currently used as the first and second line prophylactic regimens. Given that our prevalence was hospital based, we equally recommend large scale epidemiological studies to be done in other parts of the country to know the current GBS colonisation rate irrelevant to guide clinical decision making and public health policies towards implementation of strategies of prevention.

\section{ACKNOWLEDGEMENTS}

We thanked all patients who participated and sacrificed their time and donated samples for this study. We also particularly thank physicians, nurses and laboratory scientists whose advice given patients was rewarding to participate in this study at Dschang District Hospital for their contributions.

\section{AUTHOR CONTRIBUTIONS}

LFS, NM and CBTdesigned the study. CK, KO and ADA performed sampling and laboratory analysis, TFT and OBN performed statistical analysis. All authors participated in the write-up and approved the final version of the manuscript

\section{FUNDING}

The authors received no financial support for the research and writing of this manuscript.

COMPETING INTERESTS: None declared

\section{Provenance and peer review}

Not commissioned; externally peer reviewed

\section{DATA SHARING STATEMENT}

No additional data are available.

\section{AUTHORS INFORMATION}

1. LSF is a PhD in the Department of Biochemistry of the University of Dschang,

Cameroon.

2. NM is a Lecturer and Head of Department of Microbiology and Immunology Faculty of Health of the University of Dschang

3. CK is a student in the Department of Microbiology and Immunology Faculty of Health of the University of Dschang

4. TFT is a PhD in the Department of Biochemistry of the University of Dschang

5. OBN is a lecturer at Department Animal Biology of the University of Yaounde

6. OK is a PhD student in the Department of Biochemistry of the University of Dschang

7. ADA is a lecturer at Department Animal Biology of the University of Yaounde

8. CBT is an Associate Professor of Immunology and Molecular Biology in the Department of

Biochemistry of the University of Dschang in Cameroon and Head of Department of Biochemistry of the University of Bamenda, Cameroun.

Table 1: Relation between demographic characteristics of study participants and prevalence of GBS colonisation 


\begin{tabular}{|c|c|c|c|c|c|}
\hline Characteristic & $\begin{array}{l}\text { GBS } \\
\text { colonisation n } \\
(\%)\end{array}$ & $\begin{array}{l}\text { GBS } \\
\text { colonisation n } \\
(\%)\end{array}$ & & OR $(95 \% \mathrm{CI})$ & $\mathrm{p}$-value \\
\hline & Positive & Negative & $x^{2}$ & & \\
\hline $\begin{array}{l}\text { Age category } \\
{[?] 20 \text { 21-30 31-40 }}\end{array}$ & $\begin{array}{l}3(5.56) 42 \\
(77.78) 9(16.67)\end{array}$ & $\begin{array}{l}60(10.58) 399 \\
(70.37) 93\end{array}$ & 3.04 & $\mathrm{~N} / \mathrm{A}$ & 0.3856 \\
\hline $41-50$ & 0 & $(16.40) 15(2.65)$ & & & \\
\hline $\begin{array}{l}\text { Marrietal status } \\
\text { Single Married } \\
\text { widow }\end{array}$ & $\begin{array}{l}23(42.59) 31 \\
(57.41) 0\end{array}$ & $\begin{array}{l}300(52.91) 258 \\
(45.50) 9(1.59)\end{array}$ & 3.368 & $\mathrm{~N} / \mathrm{A}$ & 0.1857 \\
\hline $\begin{array}{l}\text { Level of } \\
\text { education }\end{array}$ & $\begin{array}{l}6(11.11) 33 \\
(61.11) 15\end{array}$ & $\begin{array}{l}99(17.46) 330 \\
(58.20) 138\end{array}$ & 1.484. & $\mathrm{~N} / \mathrm{A}$ & 0.4762 \\
\hline $\begin{array}{l}\text { Primary } \\
\text { secondary high } \\
\text { education }\end{array}$ & $(27.78)$ & $(24.34)$ & & & \\
\hline $\begin{array}{l}\text { Income Low } \\
\text { Moderate High }\end{array}$ & $\begin{array}{l}30(55.56) 24 \\
(44.44) 0\end{array}$ & $\begin{array}{l}192(33.86) 372 \\
(65.61) 3(0.53)\end{array}$ & 10.24 & $\mathrm{~N} / \mathrm{A}$ & 0.006 \\
\hline $\begin{array}{l}\text { Occupation } \\
\text { Student } \\
\text { housewife farmer } \\
\text { business nurse } \\
\text { teacher hustle } \\
\text { other }\end{array}$ & $\begin{array}{l}18(33.33) 12 \\
(22.22) 7(12.96) \\
8(14.86) 03 \\
(5.56) 3(5.56) 2 \\
(3.70)\end{array}$ & $\begin{array}{l}180(31.75) 135 \\
(23.81) 57 \\
(10.05) 102 \\
(17.99) 12(2.12) \\
42(7.41) 15 \\
(2.65) 24(4.23)\end{array}$ & 3.666 & $\mathrm{~N} / \mathrm{A}$ & 0.8173 \\
\hline
\end{tabular}

Table 2 : Relation between obstetric factors or pregnancy history and GBS colonisation

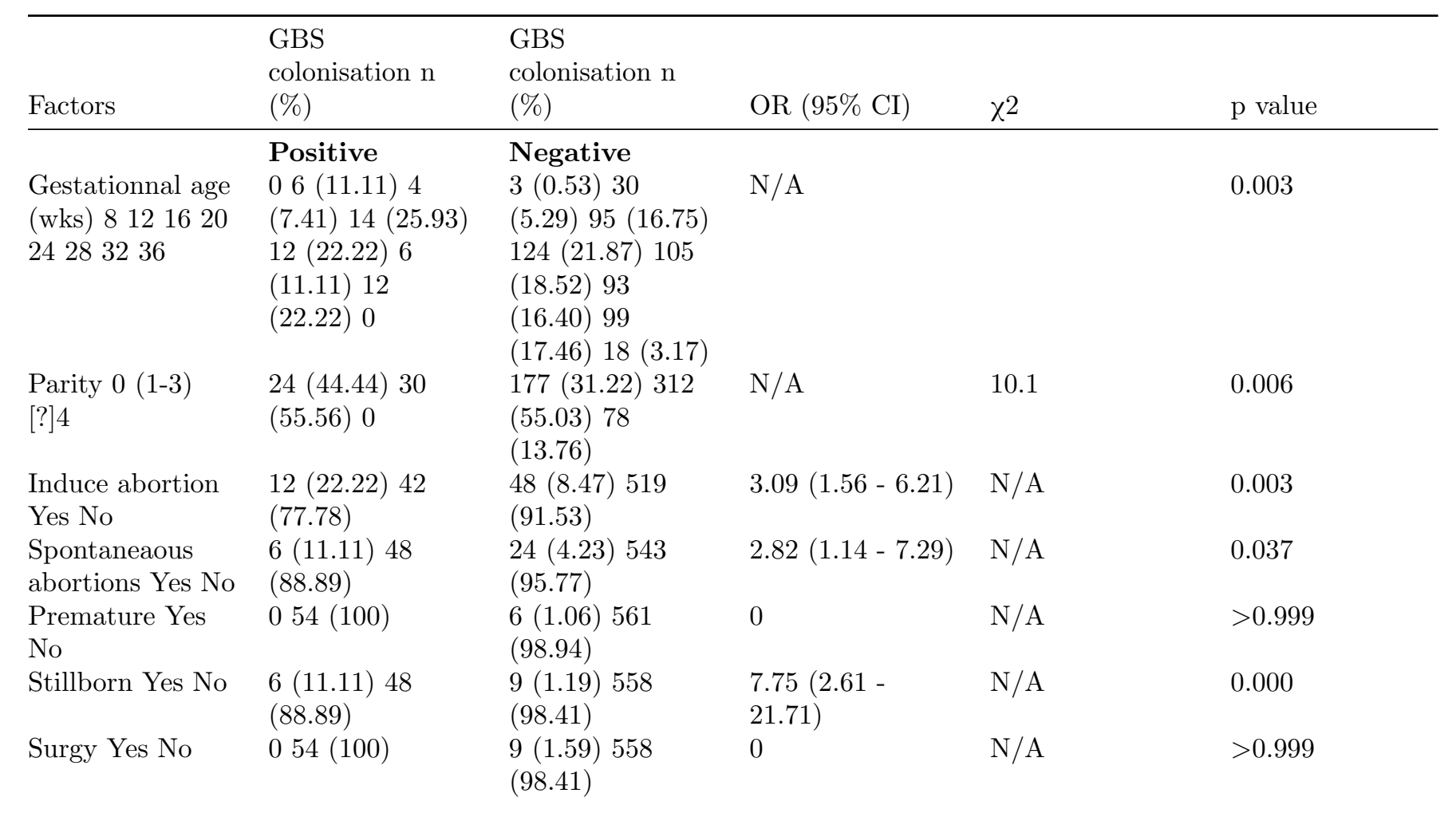




\begin{tabular}{|c|c|c|c|c|c|}
\hline Factors & $\begin{array}{l}\text { GBS } \\
\text { colonisation n } \\
(\%) \\
\end{array}$ & $\begin{array}{l}\text { GBS } \\
\text { colonisation n } \\
(\%) \\
\end{array}$ & OR $(95 \% \mathrm{CI})$ & $\chi^{2}$ & $\mathrm{p}$ value \\
\hline $\begin{array}{l}\text { Ectopic } \\
\text { pregnancy Yes } \\
\text { No }\end{array}$ & $054(100)$ & $\begin{array}{l}3(0.53) 564 \\
(99.47)\end{array}$ & 0 & $\mathrm{~N} / \mathrm{A}$ & $>0.999$ \\
\hline $\begin{array}{l}\text { Induce labour } \\
\text { Yes No }\end{array}$ & $054(100)$ & $\begin{array}{l}6(1.06) 561 \\
(98.94)\end{array}$ & 0 & $\mathrm{~N} / \mathrm{A}$ & $>0.999$ \\
\hline PROM Yes No & $054(100)$ & $\begin{array}{l}6(1.06) 561 \\
(98.94)\end{array}$ & 0 & $\mathrm{~N} / \mathrm{A}$ & $>0.999$ \\
\hline $\begin{array}{l}\text { Number of } \\
\text { prenatal visit } \\
\text { None } 12345 \\
\text { and more }\end{array}$ & $\begin{array}{l}015(27.78) 12 \\
(22.22) 15 \\
(27.78) 9(16.67) \\
3(5.56)\end{array}$ & $\begin{array}{l}42(7.41) 90 \\
(15.87) 126 \\
(22.22) 138 \\
(24.34) 69 \\
(12.17) 102 \\
(17.99)\end{array}$ & $\mathrm{N} / \mathrm{A}$ & 13.67 & 0.0178 \\
\hline $\begin{array}{l}\text { Used of } \\
\text { contraceptive } \\
\text { Yes No }\end{array}$ & $\begin{array}{l}21(38.89) 33 \\
(61.11)\end{array}$ & $\begin{array}{l}273(48.15) 294 \\
(51.85)\end{array}$ & $0.68(0.39-1.22)$ & $\mathrm{N} / \mathrm{A}$ & 0.202 \\
\hline
\end{tabular}

Table 3 : Relation between medication history or disease history and GBS colonisation in pregnant women

\begin{tabular}{|c|c|c|c|c|c|}
\hline Factors & $\begin{array}{l}\text { GBS colonisation } \\
\mathrm{n}(\%)\end{array}$ & $\begin{array}{l}\text { GBS colonisation } \\
\mathrm{n}(\%)\end{array}$ & OR $(95 \% \mathrm{CI})$ & $\chi^{2}$ & $\mathrm{p}$ value \\
\hline & Positive & Negative & & & \\
\hline $\begin{array}{l}\text { Used of } \\
\text { antibiotic Yes No }\end{array}$ & $\begin{array}{l}12(22.22) 42 \\
(77.78)\end{array}$ & $\begin{array}{l}144(25.40) 423 \\
(74.60)\end{array}$ & $0.84(0.43-1.62)$ & $\mathrm{N} / \mathrm{A}$ & 0.742 \\
\hline Fever Yes No & $\begin{array}{l}12(22.22) 42 \\
(77.78)\end{array}$ & $\begin{array}{l}246(43.39) 321 \\
(56.61)\end{array}$ & $0.37(0.19-0.71)$ & $\mathrm{N} / \mathrm{A}$ & 0.002 \\
\hline Diabetic Yes No & $054(100)$ & $\begin{array}{l}36(6.35) 531 \\
(93.65)\end{array}$ & 0 & $\mathrm{~N} / \mathrm{A}$ & $>0.999$ \\
\hline $\begin{array}{l}\text { HIV status Yes } \\
\text { No }\end{array}$ & $054(100)$ & $\begin{array}{l}18(3.17) 549 \\
(96.83)\end{array}$ & 0 & $\mathrm{~N} / \mathrm{A}$ & $>0.999$ \\
\hline $\begin{array}{l}\text { Heart disease } \\
\text { Yes No }\end{array}$ & $054(100)$ & $0567(100)$ & 0 & $\mathrm{~N} / \mathrm{A}$ & $>0.999$ \\
\hline Anemia Yes No & $\begin{array}{l}15(27.78) 39 \\
(72.22)\end{array}$ & $\begin{array}{l}360(63.49) 207 \\
(36.51)\end{array}$ & $0.22(0.12-0.43)$ & $\mathrm{N} / \mathrm{A}$ & $<0.000$ \\
\hline $\begin{array}{l}\text { UTI during } \\
\text { pregnancy Yes } \\
\text { No }\end{array}$ & $\begin{array}{l}9(16.67) 45 \\
(83.33)\end{array}$ & $\begin{array}{l}159(28.04) 408 \\
(71.96)\end{array}$ & $0.51(0.25-1.03)$ & $\mathrm{N} / \mathrm{A}$ & 0.078 \\
\hline
\end{tabular}

Table 4: Multivariate logistic regression to determine independent predictors

\begin{tabular}{llllll}
\hline Risk factors & Wald & OR & $95 \%$ CI & $95 \%$ CI & P value \\
\hline Age & 0.000 & 0.0219 & 0 & $(+$ inf $)$ & 0.999 \\
marital status & 0.000 & 7.203 & 0 & $(+$ inf $)$ & 1 \\
level of education & 0.000 & 0.000 & 0 & $(+$ inf $)$ & 0.996 \\
income & 0.000 & 0.000 & 0 & $(+$ inf $)$ & 0.999
\end{tabular}




\begin{tabular}{|c|c|c|c|c|c|}
\hline Risk factors & Wald & OR & $95 \% \mathrm{CI}$ & $95 \% \mathrm{CI}$ & $P$ value \\
\hline occupation & 0.000 & 0.000 & 0 & $(+\inf )$ & 0.993 \\
\hline gestationnal age & 0.000 & 1.269 & 0 & $(+\inf )$ & 1 \\
\hline Parity (No. of previous births & 0.000 & 0.006 & 0 & $(+\inf )$ & 0.999 \\
\hline Induced abortion & 0.000 & 0.000 & 0 & $(+\inf )$ & 0.999 \\
\hline Spontaneous abortion & 0.000 & 0.000 & 0 & $(+\inf )$ & 0.999 \\
\hline premature & 0.000 & 0.000 & 0 & $(+\inf )$ & 1 \\
\hline stillborn & 0.000 & $2.45 \mathrm{E}+14$ & 0 & $(+\inf )$ & 0.999 \\
\hline surgy & 0.000 & $>1 \mathrm{e} 40$ & 0 & $(+\inf )$ & 0.996 \\
\hline Ectopic pregnancy & 0.000 & 0.000 & 0 & $(+\inf )$ & 0.999 \\
\hline induce labour & 0.000 & $8.15 \mathrm{E}+28$ & 0 & $(+\inf )$ & 0.998 \\
\hline nombre de visite prenatal & 0.000 & 2.468 & 0 & $(+\inf )$ & 1 \\
\hline used of contraceptive & 0.000 & $9.57 \mathrm{E}+25$ & 0 & $(+\inf )$ & 0.989 \\
\hline used of antibiotics & 0.000 & $1.57 \mathrm{E}+31$ & 0 & $(+\inf )$ & 0.998 \\
\hline fever & 0.000 & $3.93 \mathrm{E}+35$ & 0 & $(+\inf )$ & 0.992 \\
\hline diabetic & 0.000 & $>1 \mathrm{e} 40$ & 0 & $(+$ inf $)$ & 0.997 \\
\hline HIV status & 0.000 & $1.41 \mathrm{E}+32$ & 0 & $(+$ inf $)$ & 0.998 \\
\hline Anaemia & 0.000 & $2.22 \mathrm{E}+36$ & 0 & $(+\inf )$ & 0.992 \\
\hline UTI during pregnancy & 0.000 & $3.02 \mathrm{E}+39$ & 0 & $(+\inf )$ & 0.998 \\
\hline
\end{tabular}

\section{Hosted file}

image1.emf available at https://authorea.com/users/396573/articles/509727-group-bstreptococcus-colonisation-prevalence-associated-risk-factors-and-antimicrobialsusceptibility-pattern-among-pregnant-women-attending-antenatal-care-at-dschangdistrict-hospital-west-region-of-cameroun-a-hospital-based-cross-sectional-study

Figure 1 : antibiotics susceptibility

Figure 1 : antibiotics suceptibility

\section{REFERENCES}

1. Chen Z, Wen G, Cao X, et al. Group B streptococcus colonisation and associated risk factors among pregnant women: A hospital-based study and implications for primary care. Int J Clin Pract . 2019;73:e13276.

2. Clouse K, Shehabi A, Suleimat AM, et al. High prevalence of Group B Streptococcus colonization among pregnant women in Amman. Jordan.BMC Pregnancy and Childbirth . 2019 ; 19:177

3. Benitz WE, Gould JB, Druzin ML. Risk factors for early-onset group B streptococcal sepsis: estimation of odds ratios by critical literature review. Pediatrics. 1999;103(6):e77.

4. Tudela CM, Stewart RD, Roberts SW, et al. McIntire DD. et al. Intrapartum evidence of early-onset group B streptococcus. Obstet Gynecol. 2012; 119 (3):626-9

5. Nan C, Dangor Z, Cutland CL, et al. Maternal group B Streptococcus-related stillbirth: a systematic review. BJOG . 2015;122(11):1437-45

6. Thigpen MC, Whitney CG, Messonnier NE, et al. Bacterial meningitis in the United States. 1998-2007. $N$ Engl J Med . 2011; 364(21):2016-25

7. Melin P and Efstratiou A. Group B streptococcal epidemiology and vaccine needs in developed countries. Vaccine . 2013;31(Suppl 4):D31-42

8. Deutscher M, Lewis M, Zell ER. et al. Incidence and severity of invasive Streptococcus pneumoniae. Group A Streptococcus and group B Streptococcus infections among pregnant and postpartum women. 
Clin Infect Dis . 2011;53:114-123.

9. Li YP, Kuok CM, Lin SY, et al. Group B Streptococcus antimicrobial resistance in neonates born to group B Streptococcus-colonized mothers: single-center survey. J Obstet Gynaecol Res. 2016;42:1471-1475.

10. Joachim A, Matee MI, Massawe FA, et al. "Maternal and neonatal colonisation of group B streptococcus at Muhimbili National Hospital in Dar es Salaam. Tanzania: Prevalence, risk factors and antimicrobial resistance." BMC Public Health . vol.9.article 437.2009.

11. Chaudhry BY. Akhtar N. Balouch AH. Vaginal carriage rate of group B Streptococcus in pregnant women and its transmission to neonates. J Ayub Med Coll Abbottabad. 2010; 22(4): 167-70. PMID: 22455289 .

12. Ndawage C, Michel T, Paul AJ. Thérèse N. Hortense G. Kouanga M. and Sinata KS. Vaginal colonization and resistant profile of group B Treptoccocus among pregnant woman in Yaoundé Gynecology. Obstetric and Pediatric Hospital Yaoundé. Journal of Clinical Medicine and Research . 2014. 6(3) : 16-21

13. Nkembe NM, Kamga HG, Baiye AW, et al. Streptococcus agalactiae prevalence and antimicrobial susceptibility pattern in vaginal and anorectal swabs of pregnant women at a tertiary hospital in Cameroon. $B M C$ Res Notes. 2018; 11:480.

14. CLSI. Performance Standards for Antimicrobial Susceptibility Testing; Twenty-Fourth Informational Supplement. CLSI document M100-S24. Wayne. PA: Clinical and Laboratory

Standards Institute. 2014.

15. Adawaye C, Michel T, Paul AJ, et al. Vaginal colonization and resistance profle of group B Streptococcus among pregnant women in Yaoundé Gynecology. Obstetric and Pediatric Hospital in Cameroon. J Clin Med Res. 2014;6: 16-21.

16. Foumane P, Mboudou E, Dohbit JS, et al. Group B beta hemolytic Streptococcus in pregnancy and its effect on maternal and foetal outcome in the Yaounde General Hospital: a descriptive study. Streptocoque beta hemolytique du groupe B et consequences materno-foetales observees a l'Hopital General de Yaounde: etude descriptive. Clin Mother Child Health . 2009; 6:995-1002.

17. Shimelis S, Mekidm M, Daniel B, et al. Prevalence of Group B Streptococcus. Its Associated Factors and Antimicrobial Susceptibility Pattern Among Pregnant Women Attending Antenatal Care at Arbaminch Hospital. South Ethiopia. American Journal of Health Research . 6 : (7). o. 6. 2019. 104-115.

18. Chen Z, Wen G, Cao X. Li S. Wang X. Yao Z. Wu C. Ye X. Group B streptococcus colonisation and associated risk factors among pregnant women: A hospital-based study and implications for primary care. Int J Clin Pract . 2019;73: e13276.

19. Clouse K, Shehabi A, Suleimat AM, et al. High prevalence of Group B Streptococcus colonization among pregnant women in Amman. Jordan. BMC Pregnancy and Childbirth. 2019 ; 19:177

20. Mohammed M, Asrat D, Woldeamanuel Y, et al. Prevalence of group B Streptococcus colonization among pregnant women attending antenatal clinic of Hawassa Health Center. Hawassa. Ethiopia. Ethiopian Journal of Health Development . 2012; 26 (1): 36-42.

21. Alemseged G, Niguse S, Hailekiros H, et al. Isolation and anti-microbial susceptibility pattern of group B Streptococcus among pregnant women attending antenatal clinics in Ayder Referral Hospital and Mekelle Health Center. Mekelle. Northern Ethiopia. Bio Med Central Research Notes . 2015; 8 (518): 1-8.

22. Mengist A, Kannan H, Abdissa A. Prevalence and antimicrobial susceptibility pattern of anorectal and vaginal group B Streptococci isolates among pregnant women in Jimma. Ethiopia. Bio Med Central Research Notes . 2016; 9 (1): 351. 
23. Namugongo A, Bazira J, Fajardot Y, et al. Group B Streptococcus Colonization among Pregnant Women Attending Antenatal Care at Tertiary Hospital in Rural Southwestern Uganda. International Journal of Microbiology Volume 2016. Article ID 3816184. 7 pages

24. Berardi A. Rossi C. Creti R. et al. Group B streptococcal colonization in 160 mother-baby pairs: a prospective cohort study. J Pediatr . 2013;163:1099-1104.

25. Le Doare K, Jarju S, Darboe S, et al. Risk factors for Group B Streptococcus colonisation and disease in Gambian women and their infants. J Infect . 2016;72: 283-294.

26. Chaudhry BY, Akhtar N, Balouch AH. Vaginal carriage rate of group B Streptococcus in pregnant women and its transmission to neonates.J Ayub Med Coll Abbottabad . 2010;22: 167-170.

27. Tsolia M, Psoma M, Gavrili S, et al. Group B Streptococcus colonization of Greek pregnant women and neonates: prevalence. risk factors and serotypes. Clin Microbiol Infect . 2003;9:832-838

28. Okike IO, Ribeiro S, Ramsay ME, et al. Trends in bacterial mycobacterial. and fungal meningitis in England and Wales 2004- 11: an observational study. Lancet Infect Dis . 2014; 14: 301-307

29. Steenwinkel D, Florentien D, Tak HV, et al. Low carriage rate of group B streptococcus in pregnant women in Maputo. Mozambique. Tropical Medicine 83 International Health. 2008; 13 (3): 427-429.

30. Darabi R, Sima T, Mohit M, et al. Bahareh K. Etminan-Bakhshn M. Parsa Y. The prevalence and risk factors of group B streptococcus colonization in Iranian pregnant women. Electronic Physician . 2017. 9(5) : 4399-4404.

31. Hakansson S, Axemo P, Bremme K, et al. Group B streptococcal carriage in Sweden: a national study on risk factors for mother and infant colonisation. Acta Obstet Gynecol Scand . 2008;87:50-58

32. Dechen TC, Sumit K, Ranabir P. Correlates of vaginal colonization with Group B streptococci among pregnant women. J Glob Infect Dis . 2010;2: 236-241.

33. Joachim A, Matee MI, Massawe FA, et al. Maternal and neonatal colonisation of group B Streptococcus at Muhimbili National Hospital in Dar es Salaam. Tanzania: prevalence. risk factors and antimicrobial resistance. BMC Public Health . 2009;9: 437.

34. Najmi N, Jehan I, Sikandar R, et al. Maternal genital tract colonsation by group-B Streptococcus: a hospital based study. J Pak Med Assoc . 2013;63: 1103-1107.

35. Anthony BF, Okada DM, and Hobel CJ, Epidemiology of group B Streptococcus: longitudinal observations during pregnancy. J Infect Dis . 1978; 137:524-530.

36. Yow MD, Leeds LJ, Thompson PK, et al. The natural history of group B streptococcal colonization in the pregnant woman and her offspring. Am J Obstet Gynecol . 1980; 137: 34-38.

37. Khatoon F, Aruna N, Sharma NR, et al. Prevalence and risk factors for group B streptococcal colonization in pregnant women in northern India. International Journal of Reproduction. Contraception. Obstetrics and Gynecology. 2016;5(12):4361-4364.

38. Dechen TC, Sumit K, and Ranabir P. Correlates of vaginal colonization with group B Streptococci among pregnant women. J Globe Infect Dis . 2010;2: 236-41.

39. Mitima KT, Ntamako S, Birindwa AM, et al. Prevalence of colonization by Streptococcus agalactiae among pregnant women in Bukavu. Democratic Republic of the Congo. J Infect Dev Ctries . 2014;8: 11951200.

40. Kim EJ, Oh KY, Kim MY, et al. Risk factors for group B Streptococcus colonization among pregnant women in Korea. Epidemiol Health . 2011; 33: e2011010 
41. Forcey DS, Vodstrcil LA, Hocking JS, et al. Factors associated with bacterial vaginosis among women who have sex with women: a systematic review. PLoS ONE . 2015;10:e0141905

42. Ness RB, Hillier SL, Richter HE, et al. Douching in relation to bacterial vaginosis. lactobacilli. and facultative bacteria in the vagina. Obstet Gynecol . 2002;100: 765.

43. Centers for Disease Control and Prevention. Prevention of perinatal group B Streptococcal disease. $M m w r$ . 2010;59:1-32.

44. Shiferawu MM, Baza D, and Lera T. Prevalence of Group b Streptococcus. Its Associated Factors and Antimicrobial Susceptibility Pattern Among Pregnant Women Attending Antenatal Care at Arbaminch Hospital. South Ethiopia. American Journal of Health Research.2019; 7(6): 104-115 